\title{
Glucose and lipoprotein biomarkers and breast cancer severity using data from the Swedish AMORIS cohort
}

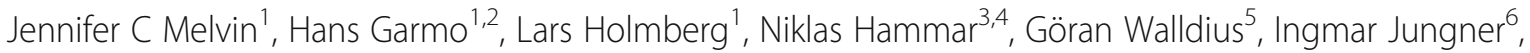
Mats Lambe ${ }^{2,7}$ and Mieke Van Hemelrijck $k^{1 *}$

\begin{abstract}
Background: The lipid and glucose metabolisms are postulated as possible intermediary mechanisms in linking obesity and breast cancer (BC). Links between serum lipid and glucose biomarkers and BC risk has been observed in the Swedish Apolipoprotein MORtality RISk (AMORIS) cohort. We conducted a follow-up analysis including information on tumour characteristics.

Methods: One thousand eight hundred twenty-four women diagnosed with $B C$, with serum biomarker levels of glucose, triglycerides, cholesterol (total, $\mathrm{HDL}$, and LDL), and apolipoproteins A-1 and B recorded in a routine health check at baseline were included. BC severity was split into categories (good, moderate, and poor prognosis) based on ER status, TNM stage, and age at diagnosis. Proportional odds models were used to obtain odds ratios (ORs) and 95\% confidence intervals $(\mathrm{Cl})$, with the interval time between baseline measurement and $\mathrm{BC}$ diagnosis accounted for.

Results: Serum glucose and the ApoB/ApoA-1 ratio showed a non-statistically significant positive association with BC severity (proportional OR: 1.25 (95\%Cl: 0.92-1.70) for glucose (</ $\geq 5.60 \mathrm{mmol} / \mathrm{L})$ and 1.31 (95\%Cl: 0.97-1.76) for ApoB/ $A-1$ ratio $(</ \geq 1)$. The proportion of severe and moderate $B C$ was modestly greater across all abnormal serum biomarker groups.

Conclusions: Despite the size and detail of data in AMORIS, we only found a modest positive association between serum levels of glucose, apoB/ApoA-1 and BC severity, suggesting that these factors are not the main players in linking obesity and BC aggressiveness.
\end{abstract}

Keywords: Breast cancer (BC), Glucose., Triglycerides., Total cholesterol., HDL cholesterol., LDL cholesterol „ Apolipoprotein A-I, Apolipoprotein B "Severity $_{\|}$Prognosis.

\section{Background}

Epidemiological evidence suggests a positive link between obesity, overweight, and risk, progression, and severity of breast cancer $(\mathrm{BC})[9,31]$. Moreover, an association between the metabolic syndrome (MetS) and a worse BC prognosis has been reported [10]. MetS is defined by a combination of at least three of the following metabolic risks: visceral obesity, elevated serum triglycerides, reduced high-density lipoprotein cholesterol, raised blood

\footnotetext{
* Correspondence: mieke.vanhemelrijck@kcl.ac.uk

${ }^{1}$ King's College London, Division of Cancer Studies, Translational Oncology and Urology Research (TOUR), Research Oncology, Guy's Hospital, 3rd Floor Bermondsey Wing, London SE1 9RT, UK

Full list of author information is available at the end of the article
}

pressure and raised serum glucose [6]. Despite evidence from in vitro research $[8,19,24]$, the specific underlying mechanisms underpinning the link between obesity, MetS, and $\mathrm{BC}$ progression have yet to be fully elucidated and epidemiological findings remain contradicting $[25,32,34,41]$.

One mechanism suggested for this association is increased oestrogen levels - sourced from the fat in adipose tissue - which are synthesised from cholesterol [17]. Leptin, insulin-like growth factors (IGF), and the lipid and glucose metabolisms have also been postulated as possible intermediate mechanisms responsible for associations between obesity and $\mathrm{BC}$ risk [7, 33]. A positive association between triglycerides and $\mathrm{BC}$ risk has been observed 
previously [13]. Moreover, the unfavourable hormonal profile (e.g., elevated insulin, oestrogen, or leptin) associated with low levels of high-density lipoprotein (HDL) is thought to increase $\mathrm{BC}$ risk [22]. There is also evidence that higher levels of low-density lipoprotein (LDL) at time of $\mathrm{BC}$ diagnosis are indicative of poor prognosis [41].

Based on data in the AMORIS cohort, a large Swedish database with information on over 800,000 men and women, we have previously identified some evidence that abnormal serum lipid profiles, measured about 8 years prior to diagnosis, may be involved in the risk of developing $\mathrm{BC}$ [35]. Furthermore, a second study within the same population indicated that increased glucose levels, even those below the diabetic threshold, are positively associated with risk of postmenopausal BC [33]. Here, we further investigated these observations by also taking into consideration information on tumour characteristics and classifying BC into categories of severity.

\section{Methods}

\section{Study Population \& Data Collection}

The Apolipoprotein Mortality Risk (AMORIS) Study has been described in detail elsewhere $(11,12)$. Briefly, the recently updated AMORIS database comprises 812,073 individuals with blood samples sent for laboratory testing to the Central Automation Laboratory (CALAB) in Stockholm, Sweden, during the period 1985 to 1996. Individuals recruited were mainly from the greater Stockholm area, and either healthy and having laboratory testing as a part of general check-up, or outpatients referred for laboratory testing. None of the participants were inpatients at the time the samples were analysed. In the AMORIS study, the CALAB database was linked to Swedish national registries such as the Swedish National Cancer Register, the Hospital Discharge Register, the Cause of Death Register, the consecutive Swedish Censuses during 1970-1990, and the National Register of Emigration using the Swedish 10-digit personal identity number, providing complete follow-up information until 31 December 2011. For the current study, we specifically made use of the linkage between AMORIS and the Quality Register for Breast Cancer [18, 26-28, 46-48, 51, 52].

The main purpose of the Regional Quality Register of Breast Cancer in the Stockholm healthcare region is to monitor the quality of care based on regional or national guidelines for $\mathrm{BC}$ management. The register includes individual information reported continuously from the clinicians on date of diagnosis, detection mode, pathological tumour-stage, tumour characteristics and primary surgical and oncological treatment for all newly diagnosed BC patients. The database is continuously updated against the National Population Register to assess current vital status of the registered patients. The Regional Quality Register of Breast Cancer in the Stockholm healthcare region started in 1976, and has a 97\% coverage, following validation against the records of the mandatory Swedish National Cancer Register.

Additional file 1: Figure S1 illustrates the cohort selection for this study. From the subgroup of 1824 women aged 20 years or older diagnosed with invasive $\mathrm{BC}$ who had their serum levels of triglyceride (TG), total cholesterol (TC), glucose, high-density lipoprotein (HDL), low-density lipoprotein (LDL) (in $\mathrm{mmol} / \mathrm{L}$ ), apolipoprotein A-I (ApoA-1), and apolipoprotein $\mathrm{B}(\mathrm{ApoB})$ measured (in $\mathrm{g} / \mathrm{L}$ ) at least 3 months prior to diagnosis, we selected all 1499 women whose diagnosis of $\mathrm{BC}$ was also registered in the Clinical Quality Register for Breast Cancer. All serum levels were dichotomised according to their medical cut-offs. For HDL, LDL, TC/HDL, LDL/HDL, and ApoB/ApoA-1 these cutoffs were based on the values used in cardiovascular disease prevention $(1.03 \mathrm{mmol} / \mathrm{l}, 4.10 \mathrm{mmol} / \mathrm{l}, 5.00,3.50$, and 1.00 respectively $[20,29,36]$. Levels of TG, TC and glucose were dichotomised based on the National Cholesterol Education Programme, WHO Diabetes guidelines and the American Heart Association/National Heart, Lung and Blood Institute (1.71, 6.50, and $5.60 \mathrm{mmol} / \mathrm{l}$, respectively) [5, 20, 23]. For each woman, we also calculated the interval time between the time from blood analyses and date of $\mathrm{BC}$ diagnosis

TC and TG were measured enzymatically, whereas ApoA-1 and B were measured by immunoturbidimentric methods, with levels standardised according to the World Health Organisation International Federation of Clinical Chemists protocols $[28,29]$. Glucose was measured enzymatically with a glucose oxidase/peroxidase method. LDL and HDL concentrations were calculated and validated, and the procedures used have been described in detail elsewhere [51]. All methods were fully automated with automatic calibration and performed at one accredited laboratory [28].

This study complied with the Declaration of Helsinki, and the ethics review board of the Karolinska Institute approved the study (diary number: 2010/1047-31/1).

\section{Data analysis}

BC was classified into three severity groups. The part of the database linked to the Regional Quality Register of Breast Cancer in the Stockholm healthcare region holds information on ER status, age at diagnosis, and TMN stage, which was used to categorise BC severity into good, moderate, and severe prognosis (Fig. 1). To validate these categories of severity we assessed how they predicted survival (i.e., are those women classified as 'severe' actually more likely to have a poorer prognosis relative to the other two severity categories) for all $\mathrm{BC}$ patients in the entire AMORIS cohort $(n=12,537)$ using a Kaplan Meier analysis. The results showed a good validity (Additional file 2: Figure S2). 


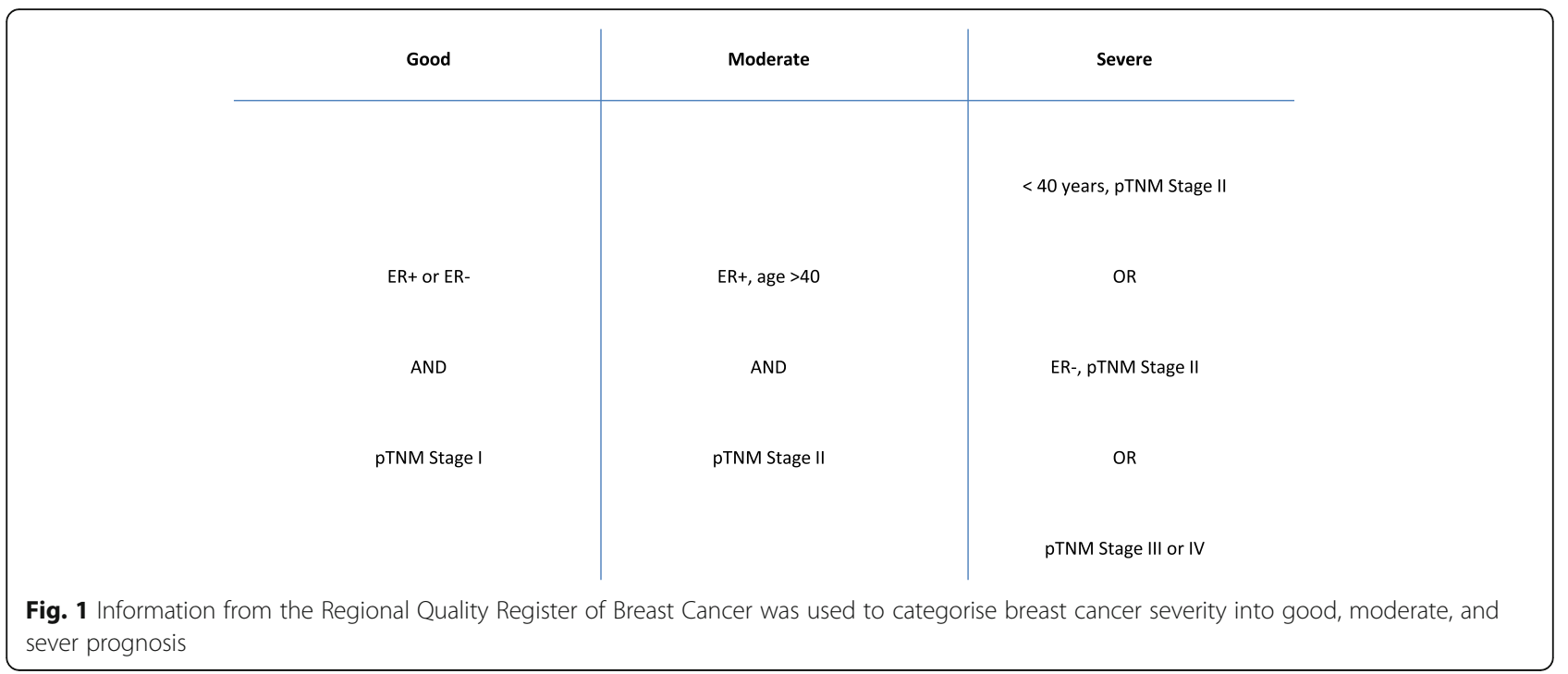

Proportional odds ratios were used to investigate associations between medical cut-offs and ratios of serum lipid and glucose components and $\mathrm{BC}$ severity, as the latter is an ordinal categorical outcome measurement. Due to lack of information, subgroup analyses could not be done for HER2 status. When not strongly correlated with the exposure variable of interest, all models were adjusted for glucose, TG and TC levels, as well as age, fasting status, parity (defined as the number of live births), Charlson Co-morbidity Index (CCI), socio-economic status (SES), and tumour characteristics. CCI was calculated through information derived from the National Patient Register. CCI considers 19 diseases, with each disease category assigned a weight $[14,30]$. The sum of an individual's weights was used to create a score, resulting in four co-morbidity levels ranging from no co-morbidity to severe co-morbidity $(0$, 1,2 , and $\geq 3$ ). No data was available on menopausal status, but age was included in the severity criteria as a proxy. It was not possible to include information on BMI as this was missing for the majority of women in the AMORIS cohort [35].

In a further analysis we stratified by interval time between baseline measurement and $\mathrm{BC}$ diagnosis to investigate the possibility of pre-diagnosed disease influencing measurement (reverse causality). If the proportional odds assumption did not hold, we performed logistic regression analyses comparing good versus moderate/poor and good/moderate versus poor, which is consistent with the comparisons made in a proportional odds model [3].

Finally, Chi-square tests were used to investigate the difference in proportions of $\mathrm{BC}$ severity at the time of diagnosis, based on medical cut-offs for each of the biomarkers measured at baseline. A figure was then created which provided a visual comparison of the differing proportions of $\mathrm{BC}$ severity at time of diagnosis. All analyses were conducted with Statistical Analysis Systems (SAS) release 9.3 (SAS Institute, Cary, NC) and R version 2.15.13 (R Foundation for Statistical Computing, Vienna, Austria).

\section{Results}

The mean interval time from baseline measurement to $\mathrm{BC}$ diagnosis was 11.6 years $( \pm 6.5 \mathrm{SD})$ in all 1824 women diagnosed with BC. Of these, 1499 had sufficient information on tumour characteristics recorded to allow definition of severity status (mean interval time 11.7 years $( \pm 6.5)$ ). Because the majority of the measurements recorded in AMORIS were taken as part of routine health check-ups, the bulk of the population (approximately $90 \%$ ) was gainfully employed (Table 1). Women with severe $\mathrm{BC}$ had the highest proportion of $\mathrm{BC}$-specific deaths $(>28 \%)$. There were no apparent differences in parity, socioeconomic status or serum biomarker distribution (Tables 1 and 2) between $\mathrm{BC}$ severity categories.

Proportional odds ratios (ORs) with 95\% confidence intervals for the association between the dichotomised serum biomarkers and $\mathrm{BC}$ severity at time of diagnosis are displayed in Table 3. Serum glucose (OR: 1.25; 95\%CI: $0.92-1.70$ ) and the ApoB/ApoA-1 ratio (OR: 1.31; 95\%CI: 0.97.05-1.76) showed greater odds of being diagnosed with a more severe $\mathrm{BC}$ in women with perturbed serum levels of these biomarkers. Thus, for those women with serum glucose levels $\geq 5.60 \mathrm{mmol} / \mathrm{l}$, the odds of severe $\mathrm{BC}$ versus the combined categories of moderate and good were 1.25 times greater, given that all of the remaining variables in the model were held constant. Similarly, because of the proportional odds assumption, the odds of the combined severe and moderate categories of $\mathrm{BC}$ versus good sees the same 
Table 1 Descriptive characteristics by breast cancer severity, including women from the AMORIS database 1989-2011

\begin{tabular}{|c|c|c|c|c|c|}
\hline & $\begin{array}{l}\text { Any BC } \\
(N=1824)\end{array}$ & $\begin{array}{l}\text { All BC w/severity } \\
(N=1411)\end{array}$ & $\begin{array}{l}\text { Good } \\
(N=900)\end{array}$ & $\begin{array}{l}\text { Moderate } \\
(N=327)\end{array}$ & $\begin{array}{l}\text { Severe } \\
(N=184)\end{array}$ \\
\hline & N (\%) & $N(\%)$ & $N(\%)$ & $N(\%)$ & $N(\%)$ \\
\hline \multicolumn{6}{|l|}{ Age at Baseline (years) } \\
\hline$\leq 49$ & $810(44.41)$ & $632(44.79)$ & $405(45.00)$ & $133(40.67)$ & $94(51.09)$ \\
\hline $50-59$ & $572(31.36)$ & $459(32.43)$ & $310(34.44)$ & $93(28.44)$ & $56(30.43)$ \\
\hline $60-69$ & $308(16.89)$ & $235(16.65)$ & $140(15.56)$ & $69(21.10)$ & $26(14.13)$ \\
\hline$\geq 70$ & $134(7.35)$ & $85(6.02)$ & $45(5.00)$ & $32(9.79)$ & $8(4.35)$ \\
\hline \multicolumn{6}{|l|}{ Mean Interval (years) } \\
\hline Time from baseline to $\mathrm{BC}(\mathrm{SD})$ & $11.56(6.46)$ & $11.70(6.52)$ & $11.71(6.42)$ & $12.67(6.85)$ & $9.91(6.06)$ \\
\hline \multicolumn{6}{|l|}{ Parity } \\
\hline Yes & $1389(76.15)$ & $1072(75.97)$ & $682(75.78)$ & $246(75.23)$ & $144(78.26)$ \\
\hline No & $435(23.85)$ & $339(24.03)$ & $218(24.22)$ & $81(24.77)$ & $40(21.74)$ \\
\hline \multicolumn{6}{|l|}{ Socioeconomic Status } \\
\hline High & $747(40.95)$ & $594(42.10)$ & $397(44.11)$ & $128(39.14)$ & $69(37.50)$ \\
\hline Low & $895(49.07)$ & $689(48.83)$ & $432(48.00)$ & $160(48.93)$ & $97(52.72)$ \\
\hline Unclassified/Missing & $182(9,98)$ & $128(9.07)$ & $71(7.89)$ & $39(11.93)$ & $18(9.78)$ \\
\hline \multicolumn{6}{|l|}{ Fasting Status } \\
\hline Fasting & $1186(65.02)$ & 888 (62.93) & 557 (61.89) & $216(66.06)$ & $115(62.50)$ \\
\hline Non-fasting & $256(14.04)$ & $204(14.46)$ & $121(13.44)$ & $43(13.15)$ & $40(21.74)$ \\
\hline Unknown & $382(20.94)$ & $319(22.61)$ & $222(24.67)$ & $68(20.80)$ & $29(15.76)$ \\
\hline \multicolumn{6}{|l|}{ Tumour Side } \\
\hline Left & 759 (50.63) & 701 (49.68) & $440(48.49)$ & $168(47.56)$ & $93(50.54)$ \\
\hline Right & 740 (49.37) & $674(47.77)$ & $428(47.56)$ & 159 (48.62) & 87 (47.28) \\
\hline Missing & $325(17.82)$ & $36(2.55)$ & $32(3.56)$ & $0(0.00)$ & $4(11.11)$ \\
\hline \multicolumn{6}{|l|}{ Invasive Grade ${ }^{a}$} \\
\hline Grade 1 & $124(6.80)$ & $113(8.01)$ & $98(10.89)$ & $14(4.28)$ & $1(0.54)$ \\
\hline Grade 2 & 296 (16.23) & $280(19.84)$ & 178 (19.78) & $93(28.44)$ & $9(4.89)$ \\
\hline Grade 3 & $170(9.32)$ & $161(11.41)$ & 70 (7.78) & $56(17.13)$ & 35 (19.02) \\
\hline Missing & $1234(67.65)$ & 857 (60.74) & $544(61.56)$ & $164(50.15)$ & $139(75.54)$ \\
\hline \multicolumn{6}{|l|}{ T-Stage } \\
\hline T0: no evidence of primary tumour & $23(1.26)$ & $21(1.49)$ & $17(1.89)$ & $1(0.31)$ & $3(1.62)$ \\
\hline $\mathrm{T} 1: \leq 2 \mathrm{~cm}$ & $1018(55.81)$ & $966(68.46)$ & $883(98.11)$ & $56(17.13)$ & $27(14.67)$ \\
\hline $\mathrm{T} 2: 2-5 \mathrm{~cm}$ & $471(25.82)$ & $365(25.87)$ & $0(0.00)$ & $256(78.29)$ & $109(59.24)$ \\
\hline T3: $>5 \mathrm{~cm}$ & $36(1.97)$ & $21(1.49)$ & $0(0.00)$ & $14(4.28)$ & $7(3.80)$ \\
\hline $\begin{array}{l}\text { T4: tumour of any size with extension } \\
\text { to the chest wall and/or skin }\end{array}$ & $41(2.25)$ & $21(1.49)$ & $0(0.00)$ & $0(0.00)$ & $38(20.65)$ \\
\hline TX: primary tumour cannot be assessed & $235(12.88)$ & $38(2.69)$ & $0(0.00)$ & $0(0.00)$ & $0(0.00)$ \\
\hline \multicolumn{6}{|l|}{ N-Stage } \\
\hline NO: negative & $1332(73.03)$ & $1233(87.38)$ & $900(100.00)$ & $227(69.42)$ & $106(57.61)$ \\
\hline N1: 1-3 & $226(12.39)$ & $167(11.84)$ & $0(0.00)$ & $100(30.58)$ & $67(36.41)$ \\
\hline N2: 4-9 & $8(0.44)$ & $5(0.35)$ & $0(0.00)$ & $0(0.00)$ & $5(2.72)$ \\
\hline$N 3: \geq 19$ & $7(0.38)$ & $6(0.43)$ & $0(0.00)$ & $0(0.00)$ & $6(3.26)$ \\
\hline Nx: nodes cannot be assessed & $251(13.76)$ & $0(0.00)$ & $0(0.00)$ & $0(0.00)$ & $0(0.00)$ \\
\hline \multicolumn{6}{|l|}{ M-Stage } \\
\hline MO: no distant spread & $1508(82.68)$ & $1390(98.51)$ & $900(100.00)$ & $327(100.00)$ & $163(88.59)$ \\
\hline
\end{tabular}


Table 1 Descriptive characteristics by breast cancer severity, including women from the AMORIS database 1989-2011 (Continued)

\begin{tabular}{|c|c|c|c|c|c|}
\hline M1: spread to distant organs & $22(1.21)$ & $21(1.49)$ & $0(0.00)$ & $0(0.00)$ & $21(11.41)$ \\
\hline $\begin{array}{l}\text { Mx: presence of metastasis cannot } \\
\text { be assessed }\end{array}$ & $294(16.12)$ & $0(0.00)$ & $0(0.00)$ & $0(0.00)$ & $0(0.00)$ \\
\hline \multicolumn{6}{|l|}{ Oestrogen Receptor Status } \\
\hline Positive & $1013(55.54)$ & $974(69.03)$ & $626(69.56)$ & $327(100.00)$ & $21(11.41)$ \\
\hline Negative & $220(12.06)$ & $213(15.10)$ & $87(9.67)$ & $0(0.00)$ & $126(68.48)$ \\
\hline Missing & $591(32.40)$ & $224(15.88)$ & 187 (20.78) & $0(0.00)$ & $37(20.11)$ \\
\hline \multicolumn{6}{|l|}{ Progesterone Receptor Status } \\
\hline Positive & $839(46.00)$ & $811(57.48)$ & $531(59.00)$ & $246(75.23)$ & $34(18.48)$ \\
\hline Negative & 379 (20.78) & $361(25.58)$ & $172(19.11)$ & $77(23.55)$ & $112(60.87)$ \\
\hline Missing & $606(33.22)$ & $239(16.94)$ & $197(21.89)$ & $4(1.22)$ & $38(20.65)$ \\
\hline \multicolumn{6}{|l|}{ HER2-status } \\
\hline Positive & $38(2.08)$ & $32(2.27)$ & $13(1.44)$ & $13(3.98)$ & $6(3.26)$ \\
\hline Negative & $289(15.84)$ & $264(18.71)$ & $172(19.11)$ & $71(21.71)$ & $21(11.41)$ \\
\hline Missing & $1497(82.07)$ & $1115(79.02)$ & $715(79.44)$ & $243(74.31)$ & $157(85.33)$ \\
\hline \multicolumn{6}{|l|}{$\mathrm{CCl}$} \\
\hline 0 & $1681(92.16)$ & $1306(92.56)$ & 834 (92.67) & 302 (92.35) & 170 (92.39) \\
\hline 1 & 70 (3.84) & $54(3.83)$ & $32(3.56)$ & $14(4.28)$ & $8(4.35)$ \\
\hline 2 & $54(2.96)$ & 35 (2.48) & $24(2.67)$ & $8(2.45)$ & $3(1.63)$ \\
\hline $3+$ & $19(1.04)$ & 16 (1.13) & $10(1.11)$ & $3(0.92)$ & $3(1.63)$ \\
\hline \multicolumn{6}{|l|}{ Dead } \\
\hline BC-Death & 245 (13.43) & $371(26.29)$ & $56(6.22)$ & 48 (14.68) & $60(32.61)$ \\
\hline
\end{tabular}

anly diagnoses taken from the Breast Cancer Quality Register will have information available

increase of 1.25 times greater, given that all of the remaining variables in the model were held constant. In a further analysis we stratified by interval time, but did not observe any consistent pattern (results not shown). Additional adjustment where interval time was included in the model as a continuous variable also did not change the above findings (results not shown).

The proportion of severe and moderate $\mathrm{BC}$ was greater across all perturbed serum biomarker groups, with a statistical difference observed for the ApoB/ApoA-1 ratio $(p$-value $=0.03)$ (Table 3$)$. For example, for serum levels of ApoA-1, the proportion of moderate and severe BCs was greater in women with reduced levels of ApoA-1 $(<1.05 \mathrm{mmol} / \mathrm{l})$. In agreement with the proportional ORs, the proportion of women with severe and moderate $\mathrm{BC}$ was moderately greater in women with elevated serum glucose levels compared to those with normal glucose levels. Similarly the proportion of moderate and severe $\mathrm{BCs}$ was higher for those with elevated values for the ApoB/ApoA-1 ratio. The distribution of BC severity was graphically illustrated to further evaluate the associations observed with lipid levels (Fig. 2).

Finally, we tested for an interaction term between interval time (time between baseline measurement and BC diagnosis) and each serum biomarker, but did not identify any statistically significant effect modification by interval time (results not shown).

\section{Discussion}

Only a weak positive association between both serum glucose and the ApoB/ApoA-1 ratio and the odds of a more severe $\mathrm{BC}$ at time of diagnosis was observed. For every serum biomarker studied, the overall proportion of moderate and severe BCs was greater amongst women with clinically abnormal values, compared to women with values within the normal clinical range. However, the differences in proportions were small. When investigating a possible modifying effect of the interval time between the measurement and $\mathrm{BC}$ diagnosis, no significant patterns were found.

Components of the MetS, particularly obesity, dyslipidemia, and diabetes have rapidly become health issues around the world, and have been independently associated with an increased risk of BC, especially postmenopausal BC $[1,4,15]$. Increased adiposity is associated with insulin resistance and dyslipidemia, both of which have been shown to increase $\mathrm{BC}$ risk $[16,42]$.

\section{The glucose metabolism}

Based on epidemiological studies, it is thought that elevated serum glucose increases the risk of BC. For example, 
Table 2 Serum lipids, lipoproteins, and glucose by breast cancer severity, including women from the AMORIS cohort 1989-2011

\begin{tabular}{|c|c|c|c|c|c|}
\hline & $\begin{array}{l}\text { Any BC } \\
(N=1824)\end{array}$ & $\begin{array}{l}\text { All BC w/severity } \\
(N=1411)\end{array}$ & $\begin{array}{l}\text { Good } \\
(N=900)\end{array}$ & $\begin{array}{l}\text { Moderate } \\
(N=327)\end{array}$ & $\begin{array}{l}\text { Severe } \\
(N=184)\end{array}$ \\
\hline & $N(\%)$ & $N(\%)$ & $\mathrm{N}(\%)$ & $\mathrm{N}(\%)$ & $N(\%)$ \\
\hline \multicolumn{6}{|c|}{ Total Cholesterol (mmol/l) } \\
\hline$<6.50$ & $1333(73.08)$ & $1040(73.71)$ & $671(74.56)$ & $231(70.64)$ & $138(75.00)$ \\
\hline$\geq 6.50$ & $491(26.92)$ & $371(26.29)$ & $229(25.44)$ & $96(29.36)$ & $46(25.00)$ \\
\hline \multicolumn{6}{|c|}{ Triglycerides (mmol/l) } \\
\hline$<1.71$ & $1592(87.28)$ & $1237(87.67)$ & $793(88.11)$ & $283(86.54)$ & $161(87.50)$ \\
\hline$\geq 1.71$ & $232(12.72)$ & $174(12.33)$ & $107(11.89)$ & $44(13.46)$ & $23(12.50)$ \\
\hline \multicolumn{6}{|c|}{ Glucose $(\mathrm{mmol} / \mathrm{l})$} \\
\hline$<5.60$ & $1590(87.17)$ & $1231(87.24)$ & $797(88.56)$ & $273(83.49)$ & $161(87.50)$ \\
\hline$\geq 5.60$ & $234(12.83)$ & $180(12.76)$ & $103(11.44)$ & $54(16.51)$ & $23(12.50)$ \\
\hline \multicolumn{6}{|c|}{$\mathrm{HDL}(\mathrm{mmol} / \mathrm{l})$} \\
\hline$\geq 1.03$ & $1763(96.66)$ & $1364(96.67)$ & $872(96.89)$ & $313(95.72)$ & $179(97.28)$ \\
\hline$<1.03$ & $61(3.34)$ & $47(3.33)$ & $28(3.11)$ & $14(4.28)$ & $5(2.72)$ \\
\hline \multicolumn{6}{|c|}{ LDL (mmol/l) } \\
\hline$<4.10$ & $1325(72.64)$ & $1032(73.14)$ & $665(73.89)$ & $231(70.64)$ & $136(73.91)$ \\
\hline$\geq 4.10$ & $499(27.36)$ & $379(26.86)$ & $235(26.11)$ & $96(29.36)$ & $48(26.09)$ \\
\hline \multicolumn{6}{|c|}{ Apolipoprotein A (g/L) } \\
\hline$\geq 1.05$ & $1811(99.29)$ & $1402(99.36)$ & $896(99.56)$ & 324 (99.08) & $182(98.91)$ \\
\hline$<1.05$ & $13(0.71)$ & $9(0.64)$ & $4(0.44)$ & $3(0.92)$ & $2(1.09)$ \\
\hline \multicolumn{6}{|c|}{ Apoliporotein B (g/L) } \\
\hline$<1.50$ & $1556(85.31)$ & $1208(85.61)$ & 781 (86.78) & $269(82.26)$ & $158(85.87)$ \\
\hline$\geq 1.50$ & $268(14.69)$ & $203(14.39)$ & 119 (13.22) & $58(17.74)$ & $26(14.13)$ \\
\hline \multicolumn{6}{|c|}{$\log (T G / H D L)$} \\
\hline$<0.50$ & $1701(93.26)$ & $1317(93.34)$ & $846(94.00)$ & $302(92.35)$ & $169(91.85)$ \\
\hline$\geq 0.50$ & $123(6.74)$ & $94(6.66)$ & $54(6.00)$ & $25(7.65)$ & $15(8.15)$ \\
\hline \multicolumn{6}{|l|}{ LDL/HDL } \\
\hline$<3.50$ & $1658(90.90)$ & $1280(90.72)$ & $824(91.56)$ & 289 (88.38) & 167 (90.76) \\
\hline$\geq 3.50$ & $166(9.10)$ & $131(9.28)$ & $76(8.44)$ & $38(11.62)$ & $17(9.24)$ \\
\hline \multicolumn{6}{|c|}{ ApoB/ApoA-I } \\
\hline$<1.00$ & $1496(82.02)$ & $1165(82.57)$ & $761(84.56)$ & $258(78.90)$ & $146(79.35)$ \\
\hline$\geq 1.00$ & $328(17.98)$ & $246(17.43)$ & $139(15.44)$ & $69(21.10)$ & $38(20.65)$ \\
\hline
\end{tabular}

a Chinese cohort study found that women with abnormal glucose markers, measured several years prior to their diagnoses, had a $\mathrm{BC}$ prevalence ratio of 1.56 (95\% CI: 1.21-2.00) [11]. However, a similar investigation into the significance of glucose in the risk of developing $\mathrm{BC}$ in the Framingham heart study-offspring cohort found only a non-significant increased risk [39].

The rise in serum glucose levels, which accompanies insulin resistance, has also been cited to result in a worse prognosis, but only in postmenopausal BC [37, 49, 53]. While hyperglycaemia has been reported as a possible mechanism, it is not thought to be the primary candidate, with insulin-like growth factor 1 (IGF-1) believed to have a greater influence [53]. Here we saw a weak trend between elevated serum glucose levels and a poor BC prognosis, although the risk was not particularly large. This could potentially be explained by hyperglycaemia being a symptom of hyperinsulinaemia (as a consequence of insulin resistance), and perhaps a stronger association would be have been found if IGF-1 were investigated directly.

\section{The lipid metabolism}

Previously in AMORIS we found weak evidence that abnormal serum lipid profiles may be involved in the risk of developing $\mathrm{BC}$ [35]. However, existing literature has cited associations between other components of the lipid 
Table 3 Proportional odds ratios (OR) and 95\% confidence intervals (Cl) for breast cancer severity from a multivariate model, including women from the AMORIS database and the Swedish Breast Cancer Registry between the years 1989-2011. Models were adjusted for age, parity, socioeconomic status, fasting status, total cholesterol, glucose, triglycerides, and interval time (except where stated otherwise)

\begin{tabular}{|c|c|c|c|}
\hline & All BC w/severity $(N=1411)$ & Crude Model & Adjusted Model \\
\hline & $N(\%)$ & OR $(95 \% \mathrm{Cl})$ & $\mathrm{OR}(95 \% \mathrm{Cl})$ \\
\hline \multicolumn{4}{|c|}{ Total Cholesterol $(\mathrm{mmol} /)^{\mathrm{a}}$} \\
\hline $\log T C$ & & $1.14(0.66-1.97)$ & $0.96(0.51-1.83)$ \\
\hline$<6.50$ & $1040(73.71)$ & 1.00 (ref) & 1.00 (ref) \\
\hline$\geq 6.50$ & $371(26.29)$ & $1.19(0.95-1.49)$ & $1.08(0.85-1.38)$ \\
\hline \multicolumn{4}{|l|}{ Triglycerides $(\mathrm{mmol} /)^{\mathrm{b}}$} \\
\hline $\log T G$ & & $1.22(1.00-1.50)$ & $1.21(0.96-1.53)$ \\
\hline$<1.71$ & $1237(87.67)$ & 1.00 (ref) & 1.00 (ref) \\
\hline$\geq 1.71$ & $174(12.33)$ & $1.13(0.84-1.52)$ & $1.00(0.72-1.37)$ \\
\hline \multicolumn{4}{|l|}{$\mathrm{HDL}(\mathrm{mmol} / \mathrm{l})$} \\
\hline Log HDL & & $0.66(0.45-0.98)$ & $0.73(0.44-1.21)$ \\
\hline$\geq 1.03$ & $1364(96.67)$ & 1.00 (ref) & 1.00 (ref) \\
\hline$<1.03$ & $47(3.33)$ & $1.10(0.63-1.90)$ & $0.89(0.47-1.67)$ \\
\hline \multicolumn{4}{|l|}{$\mathrm{LDL}(\mathrm{mmol} / \mathrm{l})$} \\
\hline Log LDL & & $1.23(0.87-1.74)$ & $2.09(0.92-4.78)$ \\
\hline$<4.10$ & $1032(73.14)$ & 1.00 (ref) & 1.00 (ref) \\
\hline$\geq 4.10$ & $379(26.86)$ & $1.12(0.89-1.40)$ & $1.07(0.76-1.50)$ \\
\hline \multicolumn{4}{|l|}{ ApoA (g/L) } \\
\hline $\log A p o A$ & & $0.49(0.25-0.98)$ & $0.56(0.27-1.15)$ \\
\hline$\geq 1.05$ & $1402(99.36)$ & 1.00 (ref) & 1.00 (ref) \\
\hline$<1.05$ & $9(0.64)$ & $2.12(0.67-6.69)$ & $1.99(0.62-6.35)$ \\
\hline \multicolumn{4}{|l|}{ ApoB (g/L) } \\
\hline $\log A p o B$ & & $1.23(0.82-1.85)$ & $1.30(0.60-2.81)$ \\
\hline$<1.50$ & $1208(85.61)$ & 1.00 (ref) & 1.00 (ref) \\
\hline$\geq 1.50$ & $203(14.39)$ & $1.25(0.95-1.65)$ & $1.22(0.85-1.74)$ \\
\hline \multicolumn{4}{|l|}{ Glucose $(\mathrm{mmol} /)^{c}$} \\
\hline Log Glucose & & $1.76(0.99-3.14)$ & $1.63(0.88-3.01)$ \\
\hline$<5.60$ & $1231(87.24)$ & 1.00 (ref) & 1.00 (ref) \\
\hline$\geq 5.60$ & $180(12.76)$ & $1.38(1.04-1.84)$ & $1.25(0.92-1.70)$ \\
\hline \multicolumn{4}{|l|}{$\log (T G / H D L)^{b, c}$} \\
\hline $\log \mathrm{TG} / \mathrm{HDL}$ & & $1.19(1.02-1.39)$ & $1.16(0.99-1.38)$ \\
\hline$<0.50$ & $1317(93.34)$ & 1.00 (ref) & 1.00 (ref) \\
\hline$\geq 0.50$ & $94(6.66)$ & $1.32(0.90-1.94)$ & $1.16(0.78-1.74)$ \\
\hline \multicolumn{4}{|l|}{ LDL/HDL } \\
\hline Log LDL/HDL & & $1.27(1.00-1.62)$ & $1.29(0.93-1.78)$ \\
\hline$<3.50$ & $1280(90.72)$ & 1.00 (ref) & 1.00 (ref) \\
\hline$\geq 3.50$ & $131(9.28)$ & $1.22(0.87-1.71)$ & $1.10(0.74-1.63)$ \\
\hline \multicolumn{4}{|l|}{ ApoB/ApoA-1 } \\
\hline Log ApoB/ApoA-1 & & $1.38(0.98-1.95)$ & $1.37(0.88-2.15)$ \\
\hline$<1.00$ & $1165(82.57)$ & 1.00 (ref) & 1.00 (ref) \\
\hline$\geq 1.00$ & $246(17.43)$ & $1.36(1.05-1.75)$ & $1.31(0.97-1.76)$ \\
\hline
\end{tabular}

${ }^{a}$ Not adjusted for TC; ${ }^{\mathrm{b}}$ Not adjusted for TG; ${ }^{\mathrm{c}}$ Not adjusted for glucose 


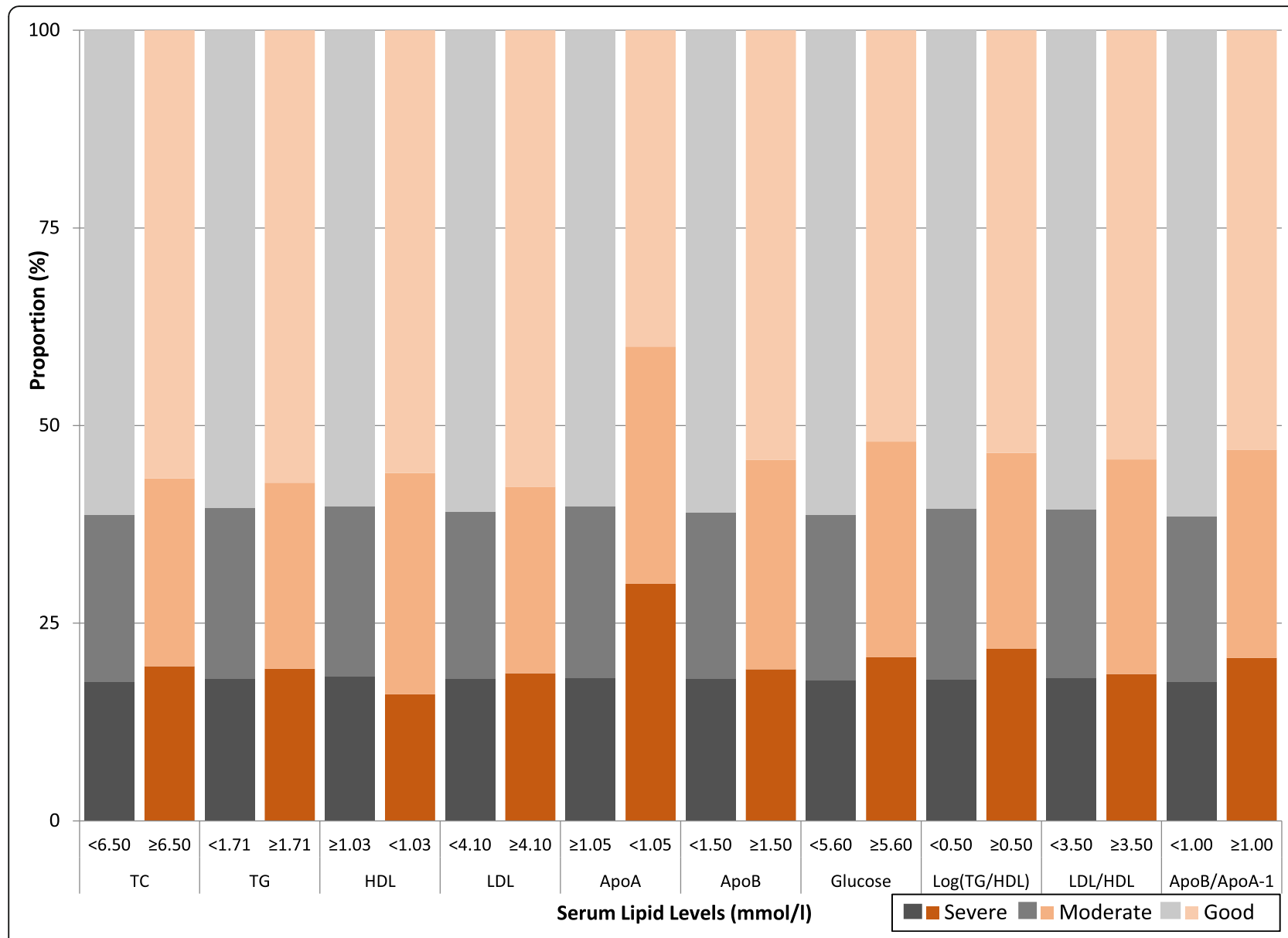

Fig. 2 Proportion of breast cancer severities within each dichotomised serum biomarker

metabolism. For example, increased triglycerides have been found to be associated with BC risk [13] as well as low HDL levels [22]. The latter was confirmed in another study, which also noted an inverse association between $\mathrm{BC}$ risk and serum levels of $\mathrm{TC}$ and ApoA-1 [25]. On the contrary, although no comment was made on BC severity, the MetS has been proposed as a risk factor for $\mathrm{BC}$ in postmenopausal women only $[2,12]$. However, in our current study, we did not observe associations with regards to $\mathrm{BC}$ severity for these serum lipid markers. This contrast with our previous AMORIS studies may thus be due to the different epidemiological framework studied: the etiologic (i.e. $\mathrm{BC}$ versus non- $\mathrm{BC}$ ) versus the prognostic (i.e. breast cancer patient only) setting.

Additionally, some studies suggest that ApoA-1 is associated with a decreased $\mathrm{BC}$ risk [25, 38]. Recent studies also raised the question as to whether the ratio of ApoB to ApoA-1 may be an independent risk predictor $[43,44,50]$. Thus, we incorporated these measurements into our investigation into BC severity. This ratio reflects the balance between all atherogenic ApoBcontaining lipoprotein particles and ApoA-I, indicating athero-protective particles [44, 45]. Our observation of a weak trend between the apoB/apoA-1 ratio and $\mathrm{BC}$ severity may reflect characteristics of the MetS such as abdominal obesity playing a role in $\mathrm{BC}$ development however, experimental evidence is needed to support this hypothesis.

It was of interest to study the interval time between baseline measurement and $\mathrm{BC}$ diagnosis, as one could assume that those with more severe $\mathrm{BC}$ may have had their disease for a longer time, which would reflect in reverse causation: the undiagnosed $\mathrm{BC}$ may be associated with perturbed serum lipid levels. Furthermore, even among women with less severe $\mathrm{BC}$ it is possible that lipid levels in the short time prior to diagnosis may already be affected by the process of carcinogenesis [21]. However, in our study we did not find any interaction with interval time.

Measurement of these biomarkers at an average of 11 years prior to the diagnosis of breast cancer has both benefits and disadvantages. The true distribution of induction and promotion times for breast cancer is not known. It is likely that the time window of exposure in this 
study reflects induction and unlikely that reverse causation by the presence of an established cancer is playing a role. However, it is plausible that the lipid metabolism changed substantially in the period between measurement and diagnosis due to lifestyle changes. Alternatively, it could be possible that the individual develops another co-morbidity (e.g., coronary heart disease, or diabetes) which acts as a competing risk, and may result in death prior to diagnosis of a cancer ([40]. However, the AMORIS cohort is still relatively young and competing risks due to cardiovascular and metabolic disease would be a threat mainly in follow-up of women aged 70 and older. To take into account these potential effects, it would be of interest to have a study setting where measurements are repeated over time - hence, it is a limitation that our study was only based on single measurements.

A major strength of the AMORIS database is its large size, and prospective blood profile measurements for all individuals, measured at the same laboratory (CALAB). The small number of women with abnormal values for certain biomarkers may have caused insufficient statistical power to detect significant associations. However, when using the continuous log value of these biomarkers none of the results changed. Additionally, we included $\mathrm{CCI}$ in the models to account for potential confounding by diabetes, BMI, smoking habits, diet, or hypertension. Previously, a limitation of the AMORIS database was the lack of information on tumour characteristics, which has now been accommodated by the recent linkage to the Breast Cancer Quality Register. We did not have data on menopausal status, but age at time of diagnosis was included in our definition of BC severity and an additional stratification by age was conducted.

\section{Conclusion}

High levels of serum glucose and the ApoB/ApoA-1 ratio were observed to be only modestly associated with higher odds of having more severe $\mathrm{BC}$. Thus, in spite of the size and great detail of the data in AMORIS, we only found a modest positive association between serum levels of glucose, apoB/ApoA-1 and BC severity, suggesting that these factors are not the main players in the link between obesity and $\mathrm{BC}$ aggressiveness.

\section{Additional files}

Additional file 1: Figure S1. Overview of the study cohort. (PPTX $32 \mathrm{~kb}$ )

Additional file 2: Figure S2. A Kaplan-Meier curve for survival in all breast cancer patients in the AMORIS cohort, by severity status

( $n=12,537)$ assessed at diagnosis. (PPTX $45 \mathrm{~kb}$ )

\section{Abbreviations}

95\%Cl: 95\% Confidence Interval; AMORIS: Apolipoprotein Mortality Risk; Apo: Apolipoprotein; BC: Breast cancer; CALAB: Central Automation Laboratory; CCl: Charlson Comorbidity Index; HDL: High density lipoprotein;
HR: Hazard Ratio; IGF: Insulin-like growth factors (IGF); LDL: Low density lipoprotein; TC: Total cholesterol; TG: Triglycerides

\section{Acknowledgements}

Not applicable.

\section{Funding}

This research was supported by the Swedish Cancer Society, the Swedish Research Council for Working Life and Social Research, the Ingmar and Gunnar Jungner Foundation, and Cancer Research UK (CRUK).

\section{Availability of data and material}

Data from the AMORIS cohort can be made available upon contacting the steering committee: http://ki.se/en/meb/amoriscancer-metabolicprofiles-and-cancer

\section{Authors' contributions}

Study design: JM, MVH Statistical analysis and interpretation: $H G, J M, M V H$, LH. Manuscript preparation: JM. Critical review of manuscript: JM, HG, LH, $\mathrm{MVH}, \mathrm{ML}, \mathrm{NH}, \mathrm{IJ}, \mathrm{GW}$. All authors read and approved the final manuscript.

\section{Competing interests}

The authors declared that they have no competing interests.

\section{Consent for publication}

NA

\section{Ethics approval and consent to participate}

This study complied with the Declaration of Helsinki, and the ethics review board of the Karolinska Institute approved the study (diary number: 2010/ 1047-31/1). As with all national register data studies in Sweden, the need for consent has been waived by the ethics review board of the Karolinska Institute.

\section{Author details}

${ }^{1}$ King's College London, Division of Cancer Studies, Translational Oncology and Urology Research (TOUR), Research Oncology, Guy's Hospital, 3rd Floor, Bermondsey Wing, London SE1 9RT, UK. Regional Cancer Centre, Uppsala/ Örebro, Uppsala, Sweden. ${ }^{3}$ Unit of Epidemiology, Insitute of Environmental Medicine, Karolinska Institutet, Stockholm, Sweden. ${ }^{4}$ AstraZeneca R\&D, Mölndal, Sweden. ${ }^{5}$ Department of Epidemiology, Institute of Environmental Medicine, Karolinska Institutet, Stockholm, Sweden. ${ }^{6}$ Department of Medicine, Clinical Epidemiological Unit, Karolinska Institutet and CALAB Research, Stockholm, Sweden. ${ }^{7}$ Department of Medical Epidemiology and Biostatistics, Karolinska Institutet, Stockholm, Sweden.

Received: 21 July 2015 Accepted: 24 March 2017

Published online: 04 April 2017

\section{References}

1. Abdulkareem $\mid H$. Aetio-pathogenesis of breast cancer. Niger Med J. 2013:54:371-5.

2. Agnoli C, Berrino F, Abagnato CA, Muti P, Panico S, Crosignani P, Krogh V. Metabolic syndrome and postmenopausal breast cancer in the ORDET cohort: a nested case-control study. Nutr Metab Cardiovasc Dis. 2010;20:41-8.

3. Agresti A. Chapter 7: Logit models for multinomial responses. Categorical Data Analysis. 2nd ed. Hoboken, New Jersey: Wiley; 2002.

4. Aguas F, Martins A, Gomes TP, De Sousa M, Silva DP, Portuguese Menopause, S, Portuguese Gynaecology, S. Prophylaxis approach to a-symptomatic post-menopausal women: breast cancer. Maturitas. 2005;52(Suppl 1):S23-31.

5. Ahn J, Lim U, Weinstein SJ, Schatzkin A, Hayes RB, Virtamo J, Albanes D. Prediagnostic total and high-density lipoprotein cholesterol and risk of cancer. Cancer Epidemiol Biomark Prev. 2009:18:2814-21.

6. Alberti KG, Eckel RH, Grundy SM, Zimmet PZ, Cleeman JI, Donato KA, Fruchart JC, James WP, Loria CM, Smith Jr SC, International diabetes federation task force on, e., prevention, hational heart, l., blood, i., american heart, a., world heart, f., international atherosclerosis, s. \& international association for the study of, o. Harmonizing the metabolic syndrome: a joint interim statement of the international diabetes federation task force on Epidemiology and prevention; National Heart, Lung, and Blood Institute; American Heart Association; world heart federation; international 
atherosclerosis society; and International Association for the Study of obesity. Circulation. 2009;120:1640-5.

7. Alegre MM, Knowles MH, Robison RA, O'neill KL. Mechanics behind breast cancer prevention - focus on obesity, exercise and dietary fat. Asian Pac J Cancer Prev. 2013;14:2207-12.

8. Antalis CJ, Arnold T, Rasool T, Lee B, Buhman KK, Siddiqui RA. High ACAT1 expression in estrogen receptor negative basal-like breast cancer cells is associated with LDL-induced proliferation. Breast Cancer Res Treat. 2010;122:661-70.

9. Azvolinsky A. Cancer prognosis: role of BMI and fat tissue. J Natl Cancer Inst. 2014;106:dju177.

10. Berrino F, Villarini A, Traina A, Bonanni B, Panico S, Mano MP, Mercandino A, Galasso R, Barbero M, Simeoni M, Bassi MC, Consolaro E, Johansson H, Zarcone M, Bruno E, Gargano G, Venturelli E, Pasanisi P. Metabolic syndrome and breast cancer prognosis. Breast Cancer Res Treat. 2014;147:159-65.

11. Bi Y, Lu J, Wang W, Mu Y, Zhao J, Liu C, Chen L, Shi L, Li Q, Wan Q, Wu S, Yang T, Yan L, Liu Y, Wang G, Luo Z, Tang X, Chen G, Huo Y, Gao Z, Su Q, Ye Z, Wang Y, Qin G, Deng H, Yu X, Shen F, Chen L, Zhao L, Zhang J, Sun J, Dai M, Xu M, Xu Y, Chen Y, Lai S, Bloomgarden ZT, Li D, Ning G. Cohort profile: risk evaluation of cancers in Chinese diabetic individuals: a longitudinal (REACTION) study. J Diabetes. 2014;6:147-57.

12. Bjorge $T$, Lukanova A, Jonsson $H$, Tretli $S$, Ulmer $H$, Manjer J, Stocks $T$, Selmer R, Nagel G, Almquist M, Concin H, Hallmans G, Haggstrom C, Stattin P, Engeland A. Metabolic syndrome and breast cancer in the me-can (metabolic syndrome and cancer) project. Cancer Epidemiol Biomark Prev. 2010;19:1737-45.

13. Capasso I, Esposito E, Pentimalli F, Crispo A, Montella M, Grimaldi M, De Marco M, Cavalcanti E, D'aiuto M, Fucito A, Frasci G, Maurea N, Esposito G, Pedicini T, Vecchione A, D'aiuto G, Giordano A. Metabolic syndrome affects breast cancer risk in postmenopausal women: National Cancer Institute of Naples experience. Cancer Biol Ther. 2010;10:1240-3.

14. Charlson ME, Charlson RE, Peterson JC, Marinopoulos SS, Briggs WM Hollenberg JP. The Charlson comorbidity index is adapted to predict costs of chronic disease in primary care patients. J Clin Epidemiol. 2008;61:1234-40.

15. Dalamaga M. Obesity, insulin resistance, adipocytokines and breast cancer: new biomarkers and attractive therapeutic targets. World J Exp Med. 2013;3:34-42.

16. Dalamaga M, Diakopoulos KN, Mantzoros CS. The role of adiponectin in cancer: a review of current evidence. Endocr Rev. 2012;33:547-94.

17. Dumitrescu RG, Cotarla I. Understanding breast cancer risk - where do we stand in 2005? J Cell Mol Med. 2005:9:208-21.

18. Eaker S, Wigertz A, Lambert PC, Bergkvist L., Ahlgren J., Lambe M. \& Uppsala/Orebro Breast Cancer, G. 2011. Breast cancer, sickness absence, income and marital status. A study on life situation 1 year prior diagnosis compared to 3 and 5 years after diagnosis.

PLoS One, 6, e18040.

19. Escrich E, Solanas M, Moral R, Escrich R. Modulatory effects and molecular mechanisms of olive oil and other dietary lipids in breast cancer. Curr Pharm Des. 2011;17:813-30.

20. Expert Panel On Detection, E. \& Treatment Of High Blood Cholesterol IN, A. Executive summary of the third report of the National Cholesterol Education Program (NCEP) expert panel on detection, evaluation, and treatment of high blood cholesterol in adults (adult treatment panel III). JAMA. 2001;285:2486-97.

21. Fossel ET, Carr JM, Mcdonagh J. Detection of malignant tumors. Watersuppressed proton nuclear magnetic resonance spectroscopy of plasma. N Engl J Med. 1986;315:1369-76.

22. Furberg AS, Jasienska G, Bjurstam N, Torjesen PA, Emaus A, Lipson SF, Ellison PT, Thune I. Metabolic and hormonal profiles: Hdl cholesterol as a plausible biomarker of breast cancer risk. The Norwegian Ebba study. Cancer Epidemiol Biomark Prev. 2005;14:33-40.

23. Grundy SM, Cleeman JI, Daniels SR, Donato KA, Eckel RH, Franklin BA, Gordon DJ, Krauss RM, Savage PJ, Smith Jr SC, Spertus JA, Costa F, American Heart A., National Heart L. \& Blood I. Diagnosis and management of the metabolic syndrome: an American Heart Association/National Heart, Lung, and Blood Institute scientific statement. Circulation. 2005;112:2735-52.

24. Hilvo M, Denkert C, Lehtinen L, Muller B, Brockmoller S, Seppanen-Laakso T, Budczies J, Bucher E, Yetukuri L, Castillo S, Berg E, Nygren H, Sysi-Aho M, Griffin UL, Fiehn O, Loibl S, Richter-Ehrenstein C, Radke C, Hyotylainen T, Kallioniemi O, Iljin K, Oresic M. Novel theranostic opportunities offered by characterization of altered membrane lipid metabolism in breast cancer progression. Cancer Res. 2011;71:3236-45.
25. His M, Zelek L, Deschasaux M, Pouchieu C, Kesse-Guyot E, Hercberg S, Galan P, Latino-Martel P, Blacher J, Touvier M. Prospective associations between serum biomarkers of lipid metabolism and overall, breast and prostate cancer risk. Eur J Epidemiol. 2014;29:119-32.

26. Holme I, Aastveit AH, Hammar N, Jungner I, Walldius G. Relationships between lipoprotein components and risk of ischaemic and haemorrhagic stroke in the Apolipoprotein MOrtality RISk study (AMORIS). J Intern Med. 2009;265:275-87.

27. Holme I, Aastveit AH, Jungner I, Walldius G. Relationships between lipoprotein components and risk of myocardial infarction: age, gender and short versus longer follow-up periods in the Apolipoprotein mortality risk study (Amoris). J Intern Med. 2008;264:30-8.

28. Jungner I, Marcovina SM, Walldius G, Holme I, Kolar W, Steiner E. Apolipoprotein B and A-I values in 147576 Swedish males and females, standardized according to the World Health Organization-International Federation of clinical chemistry first international reference materials. Clin Chem. 1998:44:1641-9.

29. Jungner I, Walldius G, Holme I, Kolar W, Steiner E. Apolipoprotein b and a-i in relation to serum cholesterol and triglycerides in 43,000 Swedish males and females. Int J Clin Lab Res. 1992;21:247-55.

30. Kastner C, Armitage J, Kimble A, Rawal J, Carter PG, Venn S. The charlson comorbidity score: a superior comorbidity assessment tool for the prostate cancer multidisciplinary meeting. Prostate Cancer Prostatic Dis. 2006;9:270-4.

31. Kulie T, Slattengren A, Redmer J, Counts H, Eglash A, Schrager S. Obesity and women's health: an evidence-based review. J Am Board Fam Med. 2011;24:75-85.

32. Laisupasin $P$, Thompat W, Sukarayodhin S, Sornprom A, Sudjaroen $Y$. Comparison of serum lipid profiles between normal controls and breast cancer patients. J Lab Physicians. 2013;5:38-41.

33. Lambe M, Wigertz A, Garmo H, Walldius G, Jungner I, Hammar N. Impaired glucose metabolism and diabetes and the risk of breast, endometrial, and ovarian cancer. Cancer Causes Control. 2011;22:1163-71.

34. Melvin JC, Holmberg L, Rohrmann S, Loda M, Van Hemelrijck M. Serum lipid profiles and cancer risk in the context of obesity: four meta-analyses. J Cancer Epidemiol. 2013;2013:823849.

35. Melvin JC, Seth D, Holmberg L, Garmo H, Hammar N, Jungner I, Walldius G, Lambe M, Wigertz A, Van Hemelrijck M. Lipid profiles and risk of breast and ovarian cancer in the Swedish AMORIS study. Cancer Epidemiol Biomark Prev. 2012;21:1381-4.

36. Millan J, Pinto X, Munoz A, Zuniga M, Rubies-Prat J, Pallardo LF, Masana L, Mangas A, Hernandez-Mijares A, Gonzalez-Santos P, Ascaso JF, Pedro-Botet J. Lipoprotein ratios: physiological significance and clinical usefulness in cardiovascular prevention. Vasc Health Risk Manag. 2009;5:757-65.

37. Minicozzi $P$, Berrino $F$, Sebastiani F, Falcini $F$, Vattiato $R$, Cioccoloni $F$, Calagreti G, Fusco M, Vitale MF, Tumino R, Sigona A, Budroni M, Cesaraccio R, Candela G, Scuderi T, Zarcone M, Campisi I, Sant M. High fasting blood glucose and obesity significantly and independently increase risk of breast cancer death in hormone receptor-positive disease. Eur J Cancer. 2013:49:3881-8.

38. Opstal-Van Winden AW, Krop EJ, Karedal MH, Gast MC, Lindh CH, Jeppsson MC, Jonsson BA, Grobbee DE, Peeters PH, Beijnen JH, Van Gils CH, Vermeulen RC. Searching for early breast cancer biomarkers by serum protein profiling of pre-diagnostic serum; a nested case-control study. BMC Cancer. 2011;11:381.

39. Parekh N, Lin Y, Vadiveloo M, Hayes RB, Lu-Yao GL. Metabolic dysregulation of the insulin-glucose axis and risk of obesity-related cancers in the Framingham heart study-offspring cohort (1971-2008). Cancer Epidemiol Biomark Prev. 2013:22:1825-36.

40. Renehan AG, Yeh HC, Johnson JA, Wild SH, Gale EA, Moller H, Diabetes \& Cancer Research, C. Diabetes and cancer (2): evaluating the impact of diabetes on mortality in patients with cancer. Diabetologia. 2012;55:1619-32.

41. Rodrigues Dos Santos C, Fonseca I, Dias S, Mendes De Almeida JC. Plasma level of Idl-cholesterol at diagnosis is a predictor factor of breast tumor progression. BMC Cancer. 2014;14:132.

42. Rose DP, Haffner SM, Baillargeon J. Adiposity, the metabolic syndrome, and breast cancer in African-American and white American women. Endocr Rev. 2007;28:763-77.

43. Schmidt C, Bergstrom G. Apolipoprotein B and Apolipopotein A-I in Vascular Risk Prediction - a Review. Curr Pharm Des. 2014;20(40):6289-98.

44. Sierra-Johnson J, Fisher RM, Romero-Corral A, Somers VK, Lopez-Jimenez F, Ohrvik J, Walldius G, Hellenius ML, Hamsten A. Concentration of apolipoprotein B is comparable with the apolipoprotein B/apolipoprotein 
A-I ratio and better than routine clinical lipid measurements in predicting coronary heart disease mortality: findings from a multi-ethnic US population. Eur Heart J. 2009;30:710-7.

45. Sniderman AD, Faraj M. Apolipoprotein B, Apolipoprotein A-I, insulin resistance and the metabolic syndrome. Curr Opin Lipidol. 2007;18:633-7.

46. Van Hemelrijck M, Garmo H, Binda E, Hayday A, Karagiannis SN, Hammar N, Walldius G, Lambe M, Jungner I, Holmberg L. Immunoglobulin E and cancer: a meta-analysis and a large Swedish cohort study. Cancer Causes Control. 2010;21:1657-67.

47. Van Hemelrijck M, Garmo H, Holmberg L, Walldius G, Jungner I, Hammar N, Lambe M. Prostate cancer risk in the swedish amoris study: the interplay among triglycerides, total cholesterol, and glucose. Cancer. 2011;117:2086-95.

48. Vichapat V, Garmo H, Holmqvist M, Liljegren G, Warnberg F, Lambe M, Fornander T, Adolfsson J, Luchtenborg M, Holmberg L. Tumor stage affects risk and prognosis of contralateral breast cancer: results from a large swedish-population-based study. J Clin Oncol. 2012;30:3478-85.

49. Villarreal-Garza C, Shaw-Dulin R, Lara-Medina F, Bacon L, Rivera D, Urzua L, Aguila C, Ramirez-Morales R, Santamaria J, Bargallo E, Mohar A, Herrera LA. Impact of diabetes and hyperglycemia on survival in advanced breast cancer patients. Exp Diabetes Res. 2012;2012:732027.

50. Walldius, G. 2012. The Apob/Apoa-l Ratio Is A Strong Predictor Of Cardiovascular Risk. In: Frank, S. A. K., G. (Ed.) Lipoproteins In Health And Diseases.

51. Walldius G, Jungner I, Holme I, Aastveit AH, Kolar W, Steiner E. High apolipoprotein B, low apolipoprotein A-I, and improvement in the prediction of fatal myocardial infarction (Amoris study): a prospective study. Lancet. 2001;358:2026-33.

52. Walldius G, Jungner I, Kolar W, Holme I, Steiner E. High cholesterol and triglyceride values in Swedish males and females: increased risk of fatal myocardial infarction. First report from the AMORIS (Apolipoprotein related MOrtality RISk) study. Blood Press Suppl. 1992;4:35-42.

53. Xu CX, Zhu HH, Zhu YM. Diabetes and cancer: associations, mechanisms, and implications for medical practice. World J Diabetes. 2014:5:372-80.

\section{Submit your next manuscript to BioMed Central and we will help you at every step:}

- We accept pre-submission inquiries

- Our selector tool helps you to find the most relevant journal

- We provide round the clock customer support

- Convenient online submission

- Thorough peer review

- Inclusion in PubMed and all major indexing services

- Maximum visibility for your research

Submit your manuscript at www.biomedcentral.com/submit 